\title{
A intervenção verbal do treinador de Voleibol na competição. Estudo com- parativo entre equipas masculinas e femininas dos escalões de formação
}

\author{
Sérgio Botelho ${ }^{1}$ \\ Isabel Mesquita ${ }^{1}$ \\ M. Perla Moreno ${ }^{2}$
}

https://doi.org/10.5628/rpcd.05.02.174

\author{
${ }^{1}$ Universidade do Porto, Faculdade de Ciências do Desporto \\ e de Educação Física, Portugal \\ ${ }^{2}$ Universidad de Extremadura, Facultad de Ciencias del \\ Deporte, Espanha
}

\begin{abstract}
RESUMO
O presente estudo teve como objectivo comparar a intervenção verbal, durante a competição, de treinadores de equipas masculinas e femininas de Voleibol. Fizerem parte da amostra 10 treinadores de equipas juvenis e juniores ( 5 de equipas masculinas e 5 de equipas femininas), considerando-se 15 sets em cada um dos grupos. Foram analisados 1790 episódios de informação (1349 durante o jogo, 388 em descontos de tempo e $53 \mathrm{em}$ período de substituição) segundo o sistema de categorias elaborado por Moreno. Os resultados mostram que os treinadores dão preferência à informação sobre a própria equipa em todos os momentos, sendo que na substituição não é dada nenhuma informação sobre a equipa contrária. Relativamente ao destinatário, durante o jogo é predominantemente individual, no desconto de tempo é fundamentalmente colectiva e na substituição é sempre individual. Na referência às acções de jogo, a informação que não se refere a nenhuma acção em concreto, inespecífica, é a mais utilizada em todos os momentos. Durante o jogo os treinadores das equipas masculinas, em termos globais, emitem significativamente mais informação do que os treinadores das equipas femininas. Particularmente, emitem de forma significativa mais informação acerca da própria equipa, com cariz inespecífico e dirigida ao colectivo.
\end{abstract}

Palavras-chave: treinador, voleibol, intervenção verbal, competição.

\begin{abstract}
The importance of verbal intervention during volleyball competition: A comparison between male and female team's coaches

The purpose of the present study was to find the importance of verbal intervention by the female and male Volleyball team's coaches during the competition. Ten coaches from junior teams ( 5 male teams and 5 female teams) volunteer to participate in this study. For each group 15 sets were considered. 1790 information episodes were analysed. All together: 1349 during the game, 388 in overtime and 53 during substitution, using the category system elaborated by Moreno. The results showed that coaches prefer the information about their own team, all the time. In the substitution time, no information about the rival team was given. With regard to the receiver it is predominantly individual based during the game, fundamentally collective in time outs and individual during substitutions. When referring to the game actions, the information that doesn't refer to any particular action, non-specific, is the most used in all moments. During the game, the coaches of the male teams generally emit more information than those of the female teams. They emit more information about their own team, with nonspecific aspect and directed to the collective.
\end{abstract}

Key Words: coach, volleyball, verbal intervention, competition. 


\section{INTRODUÇÃO}

As exigências que o desporto tem vindo a impor, na procura constante do rendimento dos jogadores e das equipas nas competições, obrigam o treinador a um conhecimento profundo acerca dos processos de intervenção, nomeadamente, durante a emissão de informação. Saber o que dizer, quando e como o dizer, constituem factores concorrentes do sucesso na intervenção pedagógica do treinador $(6,15,23$, 25). Nomeadamente no que se refere à forma de comunicar, Cushion \& Jones (6) advogam que o relacionamento estabelecido entre o treinador e os jogadores, expresso em actos e palavras, assume importância no empenhamento e rendimento individual e colectivo. Particularmente na competição, as intervenções do treinador mostram influenciar o rendimento dos jogadores, sendo referenciado por diferentes autores $(6,13,25)$ que o sucesso nas competições resulta, em grande medida, de comunicações eficazes. Considerando os resultados de um estudo em futebol de alto nível, centrado na competição (10), a informação emitida pelo treinador é apontada como um elemento relevante no rendimento da equipa, sempre que se cumprem os seguintes requisitos: que a mensagem seja audível; que se indique o nome do receptor; e que o receptor possa interpretar a mensagem de forma apropriada. No Voleibol, de acordo com o estabelecido pelo regulamento, em qualquer momento da competição o treinador pode emitir informação aos jogadores, sendo-lhe, por isso, conferidas oportunidades excepcionais de influenciar positivamente o rendimento dos jogadores/equipa. De uma forma sistemática, podemse distinguir 5 momentos nos quais o treinador emite informação: antes do jogo (os 3 minutos prévios à autorização do árbitro na realização do primeiro serviço); no desconto de tempo; nos intervalos entre sets; durante as substituições de jogadores; durante o desenrolar do jogo. A consideração de diferentes momentos do jogo, na emissão de informação pelo treinador de Voleibol, tem sido alvo de análise em investigações anteriores $(2,3,8,18,21)$, assumindo consistência o facto da informação se distinguir para os diferentes momentos e, mesmo, em cada um deles. Variáveis como o nível de rendimento das equipas (21), o resultado do set anterior (24), a equipa que solicita o tempo morto (19), o sexo dos jogadores
(3) e os momentos de emissão de informação (22) têm mostrado influenciar o teor das intervenções verbais dos treinadores. Considerando os resultados dos estudos desenvolvidos e a partir dos resultados extraídos de um questionário aplicado a treinadores experts em Voleibol, Moreno (18) estabeleceu um perfil de conduta verbal desejável para os treinadores de Voleibol nos diferentes momentos do jogo. Com o intuito de se contribuir para o incremento da investigação neste âmbito, e com a intenção de confirmar ou contrastar os resultados dos estudos anteriores, o presente estudo incide na análise da intervenção verbal dos treinadores de Voleibol em função do sexo das equipas, considerando-se para o efeito três momentos de emissão de informação - durante o jogo, desconto de tempo e substituições dos jogadores.

\section{MATERIAL E MÉTODOS \\ Amostra}

Fizeram parte do presente estudo dez $(n=10)$ treinadores de equipas juvenis e juniores inscritas nas Associações de Voleibol do Porto e de Braga, sendo 5 do sector masculino e 5 do sector feminino. As idades dos treinadores estão compreendidas entre os 21 e os 50 anos. Os treinadores das equipas masculinas possuem uma média de idade (24,6 anos) inferior à dos treinadores das equipas femininas (40,3 anos), sendo a média geral de 33,2 anos. Relativamente à experiência profissional os treinadores das equipas masculinas possuem, em média, menos anos de experiência do que os das equipas femininas (6,6 e 17,0 anos, respectivamente).

Foram observados na totalidade 10 jogos, 3 sets por jogo, no total de 30 sets, 15 nas equipas femininas e 15 para as masculinas. Registaram-se 1790 episódios de informação, dos quais 1349 correspondem ao período durante o jogo, 388 ao desconto de tempo e, por fim, 53 às substituições.

\section{Variáveis e instrumento de observação}

O estudo apresenta como variável dependente as intervenções verbais do treinador durante a competição e como variável independente o sexo das equipas. O instrumento de observação aplicado foi o de Arroyo (18) denominado "Sistema categorial para el análisis de la conducta verbal del entrenador en competición", composto pelas seguintes categorias: 
Dimensão: Equipa referenciada

Próprio - comentários do treinador sobre aspectos referentes à própria equipa.

Contrário - comentários realizados pelo treinador acerca da equipa adversária.

Dimensão: Acções de jogo

Serviço - comentários do treinador que fazem referência à acção mediante a qual se põe a bola em jogo.

Recepção - indicações do treinador acerca da acção através da qual se pretende receber e controlar o serviço adversário, de forma a enviar a bola nas melhores condições para a acção subsequente.

Distribuição - comentários do treinador referenciados à acção que pretende colocar a bola nas melhores condições para a realização do ataque e do contra-ataque.

Ataque/Contra-ataque - indicações realizadas pelo treinador relativas às acções de carácter ofensivo. Bloco - indicações do treinador acerca da primeira acção defensiva que pretende parar ou restringir as trajectórias de remate.

Defesa/Cobertura: indicações do treinador sobre as acções defensivas realizadas em $2^{\mathrm{a}}$ linha, que pretendem defender os ataques da equipa adversária ou proteger o próprio ataque.

Inespecífica - comentários realizados pelo treinador referentes ao jogo, mas que não integram de forma explícita as acções a que se referem.

Dimensão: Destinatários

Colectiva: indicações dadas pelo treinador a vários jogadores da equipa ou à equipa na totalidade.

Individual: indicações proferidas pelo treinador a um jogador.

Indefinida: indicações dadas pelo treinador onde não é evidente se a informação é dirigida a um jogador ou a vários.

\section{Procedimentos adoptados na recolha dos dados}

Num primeiro momento foi aplicado um questionário aos treinadores com a finalidade de serem recolhidas informações de índole biográfico pertinentes para o estudo. Num segundo momento os treinadores foram filmados nos seus ambientes naturais de competição. Para proceder às gravações das interven- ções verbais dos treinadores utilizámos um sistema que comporta uma câmara de vídeo fixa num tripé e um sistema audio acoplado à câmara de vídeo. Relativamente ao registo das observações, optámos pelo método de registo das ocorrências, que se caracteriza pelo registo sucessivo dos comportamentos previamente definidos.

\section{Análise dos dados}

Para analisar os conteúdos das intervenções verbais dos treinadores no decorrer do jogo recorremos à estatística descritiva, destacando as medidas de tendência central e de dispersão, nomeadamente a média, desvio-padrão, valor mínimo e máximo. Verificaram-se os pressupostos para a realização das estatísticas paramétricas, nomeadamente o $\mathrm{t}$ de Student, com o recurso ao estudo de normalidade com a prova de Kolmogorov Smirnov e com o estudo da homogeneidade das variâncias através do teste de Levene's. Nos casos em que não se verificaram estes pressupostos recorremos à estatística não paramétrica, nomeadamente o U de Mann-Whithney.

Para efeitos da interpretação e análise dos resultados, assumimos para o nível de confiança o valor de 0,05.

\section{Fiabilidade da observação}

Com a objectivo de testar a objectividade dos nossos resultados, efectuamos a análise intra-observador e inter-observador para as categorias consideradas, com base no cálculo de percentagens de acordos e desacordos registados, segundo a fórmula utilizada por Bellack (1).

Foram observados 229 episódios. Tabachnick \& Fidell (26) referem que o mínimo exigível para testar a fiabilidade das observações é de $10 \%$ do total da amostra, critério esse prescrito no presente estudo (12,8\%). Da análise dos resultados da fiabilidade intra-observador e inter-observador constatamos percentagens de $100 \%$ em todas as categorias.

\section{APRESENTAÇÃO E DISCUSSÃO DOS RESULTADOS}

\section{Análise descritiva dos dados}

Durante o jogo

No quadro 1 apresentamos os dados descritivos das intervenções verbais relativos à equipa referenciada, à acção de jogo e aos destinatários da informação durante o jogo. 
Quadro 1- Dados descritivos das intervenções verbais relativos à equipa referenciada, acção do jogo e destinatários da informação durante o jogo.

\begin{tabular}{|c|c|c|c|}
\hline \multirow[b]{2}{*}{ Equipa referenciada } & \multicolumn{3}{|c|}{ Totalidade dos treinadores } \\
\hline & $\begin{array}{c}\text { Valor } \\
\text { mínimo }\end{array}$ & $\begin{array}{c}\text { Valor } \\
\text { máximo }\end{array}$ & Média + DP \\
\hline Próprio & $6 ?$ & 275 & $134,3 \pm 66,5$ \\
\hline Contrário & 0 & 3 & $0,6 \pm 1,1$ \\
\hline \multicolumn{4}{|l|}{ Acção do jogo } \\
\hline Serviço & 2 & 45 & $13,5 \pm 14,2$ \\
\hline Recepção & 1 & 29 & $13,8 \pm 9,9$ \\
\hline Distribuição & 2 & 38 & $15,3 \pm 11,8$ \\
\hline $\begin{array}{l}\text { Ataque - contra- } \\
\text { ataque }\end{array}$ & 10 & 55 & $20,2 \pm 13,5$ \\
\hline Bloco & 6 & 36 & $19,7 \pm 11,0$ \\
\hline $\begin{array}{l}\text { Defesa / } \\
\text { Cobertura }\end{array}$ & $?$ & 36 & $21,2 \pm 8,3$ \\
\hline Inespecifica & 9 & 62 & $29,5 \pm 17,8$ \\
\hline \multicolumn{4}{|l|}{ Destinatários } \\
\hline Colectivo & 3 & 74 & $32,3 \pm 22,3$ \\
\hline Individual & 56 & 201 & $101,2 \pm 50,9$ \\
\hline Indefinido & 0 & 11 & $1,4 \pm 3,6$ \\
\hline
\end{tabular}

Pela observação do quadro 1 verificamos que os treinadores fornecem, em média, 134,3 unidades de informações relativas à própria equipa e 0,6 em relação à equipa contrária, o que é elucidativo da reduzida importância conferida pelos treinadores às informações acerca da equipa adversária. Estes resultados corroboram os do estudo de Cloes, Delhaes \& Piéron (3), no qual se concluiu que os valores de informação relativos à equipa contrária são mais reduzidos, ocorrendo, todavia, uma maior frequência destes em treinadores mais eficazes. Os especialistas (18) reforçam a importância da informação dada pelo treinador aos jogadores, na competição, acerca da equipa adversária, quando referem que deve existir equilibro na informação transmitida acerca de ambas as equipas. No presente estudo, os valores reduzidos encontrados, acerca da equipa adversária, poderão ser explicados pelo facto dos treinadores, em equipas de formação, revelarem a tendência em se preocuparem, prioritariamente, com a criação de um ambiente positivo, o que os faz centrar nos comportamentos da própria equipa, negligenciando o adversário (3).
Relativamente à dimensão Acções de jogo, as intervenções reportam-se, na sua maioria, à acção de jogo inespecífica $(29,5 \pm 17,8)$, seguindo-se a defesa/cobertura $(21,2 \pm 8,3)$, o ataque/contra-ataque $(20,2 \pm 13,5)$, o bloco $(19,7 \pm 11,0)$, a distribuição $(15,3 \pm 11,8)$, a recepção $(13,8 \pm 9,9)$ e, por fim, o serviço $(13,5 \pm 14,2)$. Estes resultados divergem do entendimento perfilhado pelos especialistas acerca das acções de jogo a serem privilegiadas pelo treinador na intervenção verbal durante a competição. Moreno (18) constatou que os treinadores experts em Voleibol consideram que a informação deve ser específica em relação aos diferentes momentos do jogo, tendo estabelecido a seguinte hierarquia: serviço, bloco, recepção, distribuição, ataque/contra-ataque e, por fim, defesa. Todavia, acrescentam que a referência do treinador aos diferentes momentos do jogo, está sempre dependente das características da própria equipa e da equipa adversária.

Podemos ainda constatar que existe um predomínio claro das informações dirigidas aos jogadores individualmente $(101,2 \pm 50,9)$, em detrimento das intervenções fornecidas ao colectivo $(32,3 \pm 22,3)$ e ao destinatário indefinido $(1,4 \pm 3,6)$. Estes resultados estão de acordo com os obtidos por Cloes, Delhaes \& Piéron (3), e com o indicado pelos treinadores experts em Voleibol (18), que propõem uma percentagem média de $63,1 \%$ de informação de cariz individual e $36,9 \%$ de predomínio colectivo. As características deste momento do jogo e a dificuldade do treinador em aceder a informar, simultaneamente, vários jogadores facilitam o predomínio da informação individual.

\section{Desconto de tempo}

No quadro 2 apresentamos os dados descritivos das intervenções verbais relativos à equipa referenciada, à acção do jogo e aos destinatários da informação no desconto de tempo. 
Quadro 2- Dados descritivos das intervenções verbais relativos à equipa referenciada, acção do jogo e destinatários da informação no desconto de tempo.

\begin{tabular}{|c|c|c|c|}
\hline \multirow[b]{2}{*}{ Equipa referenciada } & \multicolumn{3}{|c|}{ Totalidade dos treinadores } \\
\hline & $\begin{array}{c}\text { Valor } \\
\text { mínimo }\end{array}$ & $\begin{array}{c}\text { Valor } \\
\text { máximo }\end{array}$ & Média + DP \\
\hline Próprio & 15 & 52 & $37,9 \pm 12,7$ \\
\hline Contrário & 0 & 3 & $0,9 \pm 1,3$ \\
\hline \multicolumn{4}{|l|}{ Acção do jogo } \\
\hline Serviço & 0 & 4 & $1,6 \pm 1, ?$ \\
\hline Recepção & 1 & 13 & $3,1 \pm 3, ?$ \\
\hline Distribuição & 0 & 9 & $3,5 \pm 2,9$ \\
\hline $\begin{array}{l}\text { Ataque -contra- } \\
\text { ataque }\end{array}$ & 1 & 8 & $4,1 \pm 2,3$ \\
\hline Bloco & 0 & 8 & $4,6 \pm 2,6$ \\
\hline Defesa / Cobertura & 1 & 10 & $4,5 \pm 2,9$ \\
\hline Inespecifica & 5 & 31 & $17,5 \pm 10,3$ \\
\hline \multicolumn{4}{|l|}{ Destinatários } \\
\hline Colectivo & 9 & 44 & $26,8 \pm 10, ?$ \\
\hline Individual & 5 & 20 & $12,0 \pm 5, ?$ \\
\hline Indefinido & 0 & 0 & $0,0 \pm 0,0$ \\
\hline
\end{tabular}

Como se pode verificar pelo quadro 2 , durante o desconto de tempo, os treinadores estudados emitiram predominantemente informações acerca da própria equipa $(37,9 \pm 12,7)$. Os valores referentes às intervenções relativas à equipa adversária atingem valores muito reduzidos $(0.9 \pm 1,3)$, semelhantes ao constatado por Pina \& Rodrigues (22). O entendimento dos treinadores experts (18) contraria estes resultados, ao referirem que durante o desconto de tempo o treinador deve fornecer de forma equilibrada informação sobre a equipa contrária e sobre a própria equipa. No presente estudo não se verifica esta tendência, sendo evidente que os treinadores optam por informar os jogadores acerca do que se pretende alterar ou manter na própria equipa, ignorando praticamente o adversário. Ainda neste âmbito, e de acordo com Launder e Piltz (12:29) "os treinadores devem lembrar-se que ao pedirem um desconto de tempo, estão igualmente a dar ao adversário uma oportunidade de também ele fazer ajustamentos, devendo antecipar o que o treinador adversário está a pensar."

Podemos ainda verificar que, em média, os treinadores fornecem, de novo, uma elevada quantidade de informação correspondente à acção de jogo inespecífica $(17,5 \pm 10,3)$, seguindo-se o bloco $(4,6 \pm 2,6)$, a defesa/cobertura $(4,5 \pm 2,9)$, o ataque/contra-ataque $(4,1 \pm 2,3)$, a distribuição $(3,5 \pm 2,9)$, a recepção $(3,1 \pm 3,7)$ e, por último, o serviço $(1,6 \pm 1,7)$.

Os resultados verificados não são concordantes com o referenciado pelos treinadores experts em Voleibol (18), na medida em que estes enfatizam a importância da informação específica, referenciada às acções de jogo estabelecendo a seguinte hierarquia: serviço, bloco, distribuição, ataque/contra-ataque e defesa/cobertura. O facto de no presente estudo a informação sobre a aç̧ão inespecífica ser a mais utilizada pelos treinadores pode encontrar explicação na dificuldade dos treinadores em especificarem, com clareza e de forma inequívoca, a informação que pretendem fornecer aos jogadores, acabando por informar de forma imprecisa e sem objectividade. Segundo Cushion \& Jones (6) quando a informação é dada de forma rotineira e abstracta, ausente dos propósitos e conteúdos das acções de jogo, resulta num efeito de ruído de fundo perfeitamente alheio aos jovens.

Relativamente à dimensão Destinatários, como se pode observar no mesmo quadro, as informações referentes ao colectivo $(26,8 \pm 10,7)$ são as predominantes em detrimento das intervenções com cariz individual $(12,0 \pm 5,7)$. Também o estudo de Pina \& Rodrigues (21) confirma esta tendência, em virtude da informação dirigida à equipa ser a mais reforçada nas situações de desconto de tempo registando o valor de $65 \%$; contrariamente, a informação dirigida ao jogador registou apenas $1,2 \%$ e a dirigida ao grupo $9,2 \%$.

Estes resultados não corroboram a opinião dos treinadores experts em Voleibol (18), quando referem que os descontos de tempo são períodos de paragem do jogo em que a informação deve ser dirigida de uma forma equilibrada para o colectivo e individual, embora sujeita às particularidades ditadas pelo resultado e necessidades da equipa/jogadores no momento. A informação dirigida aos jogadores de acordo com a sua especialização funcional é fundamental (3, 11 ), sendo os distribuidores que devem receber maior quantidade de informação (38\%) seguidos dos atacantes e blocadores centrais $(22,4 \%)(18)$. 


\section{Substituições}

No quadro 3 apresentamos os dados descritivos das intervenções verbais relativos à equipa referenciada, à acção de jogo e aos destinatários da informação na substituição.

Pela sua leitura constata-se que a totalidade dos treinadores emite, neste período do jogo, apenas informação relativa à própria equipa $(5,3 \pm 4,7)$, o que denota ausência de preocupação em relação à equipa adversária.

De acordo com os treinadores experts a informação fornecida pelo treinador durante a substituição deve ser partilhada entre a própria equipa (54\%) e a equipa contrária $(46 \%)$, sendo conveniente que as indicações proferidas estejam contextualizadas e considerem a actuação de uma equipa em relação à outra (18).

Quadro 3- Dados descritivos das intervenções verbais relativos à equipa referenciada, acção do jogo e destinatários da informação na substituição.

\begin{tabular}{|c|c|c|c|}
\hline \multirow[b]{2}{*}{ Equipa referenciada } & \multicolumn{3}{|c|}{ Totalidade dos treinadores } \\
\hline & $\begin{array}{c}\text { Valor } \\
\text { mínimo }\end{array}$ & $\begin{array}{l}\text { Valor } \\
\text { máximo }\end{array}$ & $\begin{array}{c}\text { Média + } \\
\text { DP }\end{array}$ \\
\hline Próprio & 0 & 16 & $5,3 \pm 4, ?$ \\
\hline Contrário & 0 & 0 & $0,0 \pm 0,0$ \\
\hline \multicolumn{4}{|l|}{ Acção do jogo } \\
\hline Serviço & 0 & 2 & $0,4 \pm 0,8$ \\
\hline Recepção & 0 & 0 & $0,0 \pm 0,0$ \\
\hline Distribuição & 0 & 3 & $0,4 \pm 0,9$ \\
\hline $\begin{array}{l}\text { Ataque - contra- } \\
\text { ataque }\end{array}$ & 0 & 5 & $0,6 \pm 1,6$ \\
\hline Bloco & 0 & 1 & $0,1 \pm 0,3$ \\
\hline Defesa / Cobertura & 0 & 0 & $0,0 \pm 0,0$ \\
\hline Inespecifica & 0 & 13 & $3,8 \pm 3,6$ \\
\hline \multicolumn{4}{|l|}{ Destinatários } \\
\hline Colectivo & 0 & 0 & $0,0 \pm 0,0$ \\
\hline Individual & 0 & 16 & $5,3 \pm 4, ?$ \\
\hline Indefinido & 0 & 0 & $0,0 \pm 0,0$ \\
\hline
\end{tabular}

De realçar que a grande maioria das intervenções proferidas pelos treinadores, na substituição de jogadores, são, de novo, relativas a acções inespecíficas $(3,8 \pm 3,6)$, seguindo-se o ataque/contra-ataque $(0,6 \pm 1,6)$, o serviço $(0,4 \pm 0,8)$, a distribuição $(0,4 \pm 0,9)$ e, por fim, o bloco $(0,1 \pm 0,3)$. Estes dados apontam para a quase ausência de conteúdo na transmissão de informação, limitando-se o treina- dor, não raramente, a solicitar substituição ao árbitro, sem fornecer qualquer informação. Este facto pode estar relacionado com a possibilidade de ser emitida informação em qualquer momento do jogo, não revelando o treinador necessidade de a dar quando realiza a substituição. Todavia, de acordo com os treinadores experts (18) durante a substituição deve ser fornecida informação aos jogadores, principalmente ao jogador que vai entrar no jogo, sendo, por vezes, veículo de transmissão de informação à equipa, no sentido de se realizarem reajustamentos nas manobras ofensivas e defensivas colectivas. O motivo pelo qual se realiza a substituição, a maior ou menor incidência táctica da substituição e a especialização funcional do jogador que entra no jogo, determinam o teor da informação transmitida. No que diz respeito aos destinatários da informação, a totalidade dos treinadores transmite informações de carácter exclusivamente individual $(5,3 \pm 4,7)$, neste período do jogo. Tendo em conta os motivos que subjazem à realização das substituições, bem como a sua curta duração, percebe-se que a informação fornecida pelo treinador seja predominantemente individual (ao jogador substituído, substituto ou a outro jogador da equipa). Estes resultados confirmam o entendimento dos treinadores experts (18) ao referirem que neste período do jogo a informação deve ser predominantemente individual $(85 \%)$, em detrimento da colectiva (15\%).

\section{Análise comparativa dos resultados}

A análise comparativa recai sobre os períodos durante o jogo e no desconto de tempo. O período de substituições, em virtude do número de ocorrências ser substancialmente reduzido, não será alvo de comparação entre grupos.

\section{Durante o jogo}

No quadro 4 apresentamos os resultados comparativos das intervenções verbais durante o jogo, em função da equipa referenciada, das acções de jogo, e dos destinatários entre os treinadores das equipas masculinas e femininas. 
Quadro no 4- Dados comparativos das intervenções verbais dos treinadores de equipas masculinas e femininas durante o jogo. em função da equipa referenciada, das acções do jogo e destinatários.

\begin{tabular}{|c|c|c|c|c|}
\hline & $\begin{array}{c}\text { Equipas } \\
\text { masculinas }\end{array}$ & $\begin{array}{l}\text { Equipas } \\
\text { femininas }\end{array}$ & \multirow{2}{*}{$\begin{array}{c}\text { Valor da } \\
\text { estatística }\end{array}$} & \multirow{2}{*}{$\mathrm{p}$} \\
\hline & Média + DP & Média + DP & & \\
\hline \multicolumn{5}{|l|}{$\begin{array}{l}\text { Equipa } \\
\text { referenciada }\end{array}$} \\
\hline Próprio & $179,4 \pm 64,4$ & $89,2 \pm 25,6$ & $t=2,895$ & $0,020^{*}$ \\
\hline Contrário & $1,0 \pm 1,4$ & $0,2 \pm 0,4$ & $U=10,500$ & 0,429 \\
\hline \multicolumn{5}{|l|}{ Acções do jogo } \\
\hline Serviço & $21,8 \pm 16,4$ & $5,2 \pm 3,3$ & $\mathrm{t}=2,217$ & 0,086 \\
\hline Recepçăo & $16,4 \pm 9,1$ & $11,2 \pm 10,9$ & $\mathrm{t}=0,817$ & 0,438 \\
\hline Distribuição & $20,4 \pm 13,8$ & $10,2 \pm 7,6$ & $\mathrm{t}=1,448$ & 0,186 \\
\hline $\begin{array}{l}\text { Ataque - } \\
\text { contra-ataque }\end{array}$ & $27,0 \pm 16,5$ & $13,4 \pm 4,3$ & $t=1,779$ & 0,113 \\
\hline Bloco & $25,6 \pm 17,2$ & $13,8 \pm 5,3$ & $\mathrm{t}=1,986$ & 0,082 \\
\hline $\begin{array}{l}\text { Defesa / } \\
\text { Cobertura }\end{array}$ & $23,0 \pm 8,6$ & $19,4 \pm 8,5$ & $\mathrm{t}=0,664$ & 0,525 \\
\hline Inespecifica & $43,0 \pm 10,9$ & $16,0 \pm 11,8$ & $t=3,770$ & $0,005^{*}$ \\
\hline \multicolumn{5}{|l|}{ Destinatários } \\
\hline Colectivo & $47,0 \pm 21,9$ & $17,6 \pm 10,2$ & $\mathrm{t}=2,721$ & $0,026^{*}$ \\
\hline Individual & $130,6 \pm 57,0$ & $71,8 \pm 28,1$ & $t=2,173$ & 0,062 \\
\hline Indefinido & $2,8 \pm 4,8$ & $0,0 \pm 0,0$ & $\mathrm{U}=9,000$ & 0,329 \\
\hline $\begin{array}{l}\text { Intervenção } \\
\text { total }\end{array}$ & $180,4 \pm 65, ?$ & $89,4 \pm 26,5$ & $\mathrm{t}=2,871$ & $0,021^{*}$ \\
\hline
\end{tabular}

* Diferenças estatisticamente significativas

Em relação ao número médio de intervenções, os treinadores de equipas masculinas proferiram, de forma significativa, maior quantidade de informação em relação aos treinadores de equipas femininas $(180,4$ contra 89,4$)$.

No que diz respeito à equipa a que se refere a informação verificaram-se diferenças estatisticamente significativas, quando a informação é referente à própria equipa, sendo os valores superiores os dos treinadores das equipas masculinas. Quando a informação é respeitante à equipa adversária, verifica-se que ambos os grupos têm valores de ocorrência muito reduzidos, sendo que os treinadores de equipas masculinas transmitem, em termos médios, mais informação. No respeitante à acção do jogo sobre a qual se informa, foram registadas diferenças estatisticamente significativas na categoria inespecífica, pertencendo os valores mais elevados aos treinadores de equipas masculinas $(43,0 \pm 10,9$ contra $16.0 \pm 11,8$ nas equipas femininas).
No que concerne aos destinatários da informação, mais uma vez, os treinadores das equipas masculinas dirigem de forma significativa mais informação ao colectivo $(47,0 \pm 21,9$ contra $17,6 \pm 10,2$ nas equipas femininas), sendo que apenas os treinadores das equipas masculinas transmitiram informação com destinatários indefinidos.

Estes resultados reflectem a tendência para os treinadores de equipas masculinas emitirem mais informação, tanto em termos globais, como no que concerne à própria equipa, sendo predominantemente inespecífica e dirigida ao colectivo. Este facto, por si só, não é revelador de uma intervenção mais substantiva por parte dos treinadores das equipas masculinas, na medida em que quantidade não é sinónimo de qualidade. Não raramente, os treinadores emitem informação em demasia, sem conteúdo substantivo, funcionando mais como ruído do que propriamente como informação, para além da informação em excesso, fornecida durante o jogo, perturbar a concentração dos atletas e desviar a atenção $(6,9)$. Num estudo realizado por Cloes et al. (3) os autores verificaram que os treinadores de Voleibol não distinguem a informação transmitida, significativamente, em função dos sexo das equipas, embora se verifique a tendência de os rapazes serem mais criticados do que as raparigas e estas, por sua vez, receberem mais informação técnica.

\section{Desconto de tempo}

No quadro 5 apresentamos os resultados comparativos das intervenções verbais, em função da equipa referenciada, das acções de jogo e dos destinatários, dos treinadores de equipas masculinas e femininas no desconto de tempo. 
Quadro no 5- Dados comparativos das intervenções verbais dos treinadores de equipas masculinas e femininas no desconto de tempo, em função da equipa referenciada, das acções do jogo e destinatários.

\begin{tabular}{|c|c|c|c|c|}
\hline & $\begin{array}{c}\text { Equipas } \\
\text { masculinas }\end{array}$ & $\begin{array}{l}\text { Equipas } \\
\text { femininas }\end{array}$ & \multirow{2}{*}{$\begin{array}{c}\text { Valor da } \\
\text { estatística }\end{array}$} & \multirow{2}{*}{$\mathrm{p}$} \\
\hline & Média + DP & Média + DP & & \\
\hline \multicolumn{5}{|l|}{$\begin{array}{l}\text { Equipa } \\
\text { referenciada }\end{array}$} \\
\hline Próprio & $34,8 \pm 14,9$ & $41,0 \pm 10, ?$ & $t=-0,775$ & 0,472 \\
\hline Contrário & $1,0 \pm 1,4$ & $0,8 \pm 1,3$ & $t=0,232$ & 0,822 \\
\hline \multicolumn{5}{|l|}{ Acções do jogo } \\
\hline Serviço & $1,0 \pm 1,2$ & $2,2 \pm 2,1$ & $t=-1,124$ & 0,294 \\
\hline Recepção & $2,0 \pm 1,0$ & $4,2 \pm 5,2$ & $t=-0,926$ & 0,381 \\
\hline Distribuição & $4,0 \pm 1,6$ & $3,0 \pm 3,9$ & $t=0,527$ & 0,620 \\
\hline $\begin{array}{l}\text { Ataque - } \\
\text { contra-ataque }\end{array}$ & $4,4 \pm 2,9$ & $3,8 \pm 1,8$ & $t=0,396$ & 0,703 \\
\hline Bloco & $5,0 \pm 2,1$ & $4,2 \pm 3,2$ & $t=0,46 ?$ & 0,653 \\
\hline $\begin{array}{l}\text { Defesa / } \\
\text { Cobertura }\end{array}$ & $3,4 \pm 2,3$ & $5,6 \pm 3,3$ & $\mathrm{t}=-1,226$ & 0,255 \\
\hline Inespecifica & $16,0 \pm 10,8$ & $19,0 \pm 10, ?$ & $t=-0,440$ & 0,671 \\
\hline \multicolumn{5}{|l|}{ Destinatários } \\
\hline Colectivo & $24,6 \pm 13,1$ & $29,0 \pm 8,5$ & $t=-0,629$ & $0,54 ?$ \\
\hline Individual & $11,2 \pm 6,5$ & $12,8 \pm 5,4$ & $t=-0,420$ & 0,685 \\
\hline $\begin{array}{l}\text { Intervenção } \\
\text { total }\end{array}$ & $35,8 \pm 14,7$ & $41,8 \pm 9,9$ & $t=-0,756$ & $0,4>1$ \\
\hline
\end{tabular}

Podemos constatar, em termos médios, maior número de intervenções dos treinadores de equipas femininas, neste período do jogo, embora sem significado estatístico. Em relação à equipa a que se refere a informação, não foram registadas diferenças estatisticamente significativas, emitindo ambos os grupos reduzida informação acerca da equipa adversária. No tocante à acção de jogo sobre o qual se informa, do mesmo modo, os resultados não expressam significado estatístico, registando-se nos dois grupos o predomínio da informação relativa à acção de jogo inespecífica. Em relação às restantes categorias podemos constatar que o serviço, a recepção e a defesa atingem valores superiores nos treinadores de equipas femininas. As tendências evolutivas do jogo de Voleibol mostram que o serviço continua a ser uma "arma" fundamental no jogo feminino, sendo a recepção a primeira acção realizada após o serviço e crucial na organização ofensiva (7). Em relação à defesa, a supremacia de informação emitida pelos treinadores das equipas femininas poderá ser justificada pelo facto de o jogo feminino se basear, predominantemente, nas acções defensivas e, consequentemente, o sucesso resultar, em grande medida, da capacidade de sustentação da bola $(5,17,27)$. Por seu turno, os treinadores das equipas masculinas mostram valores mais elevados quando fornecem informação sobre a distribuição, ataque/contra-ataque e bloco, devido ao jogo masculino ser mais rápido, com mais combinações ofensivas, assumindo o bloco protagonismo na anulação do ataque adversário (16).

No respeitante aos destinatários da informação, os valores são muito semelhantes entre os dois grupos, com realce para a informação dirigida para toda a equipa (colectivo). Este resultado era de esperar, em virtude do desconto de tempo ser um período, por excelência, consignado ao reforço de informação pertinente para toda a equipa. Todavia, a informação individual não deve ser negligenciada, função das necessidades pontuais do momento do jogo e da especialização funcional dos jogadores (18).

\section{CONCLUSÕES}

Dos resultados do presente estudo ressalta que os treinadores privilegiam a informação acerca da própria equipa, em detrimento da informação fornecida acerca da equipa adversária, em todos os períodos de emissão de informação analisados (durante o jogo, desconto de tempo e substituições). Esta constatação é reveladora de uma centração excessiva dos treinadores sobre a sua equipa, descurando as informações relevantes que importa considerar acerca do jogo do adversário. O equilíbrio na informação transmitida pelo treinador acerca da própria equipa e do adversário é apontado como factor preditivo da eficácia da intervenção do treinador durante a competição (18). No que concerne ao conteúdo da informação este recai, sobretudo, na acção de jogo inespecífica, tanto durante o jogo, como no desconto de tempo e nas substituições. Este aspecto demonstra que os treinadores não valorizam a informação específica acerca das acções de jogo, o que resulta numa informação vaga e pouca dirigida para a tarefa. Importa contrariar esta tendência no treino de crianças e jovens, em virtude de ser fundamental que o treinador seja capaz de especificar de forma clara, objectiva e precisa as informações acerca das acções de jogo. Não raramente, a informação inespecífica é sinónimo de 
ruído para os jogadores, habituando-se estes à sua presença, mas não prestando qualquer atenção ao seu significado e apropriação.

Relativamente ao destinatário, os treinadores divergem o perfil de intervenção em função das características do período em que emitem informação. Durante o jogo é, prioritariamente, individual, no desconto de tempo é, fundamentalmente, colectiva e nas substituições é, exclusivamente, individual. Estes resultados corroboram de um forma geral o considerado pelos treinadores experts (18), embora no desconto de tempo a distribuição equilibrada da informação emitida à equipa e aos jogadores individualmente, seja, cada vez mais, uma necessidade, imposta pela especialização funcional e pela desejada retenção de informação, por parte do jogador, em relação a aspectos considerados essenciais e que só a ele interessam.

$\mathrm{Na}$ comparação entre grupos, o presente estudo demonstrou que o sexo das equipas é uma variável discriminativa da quantidade de informação emitida pelos treinadores durante o jogo. Assim, os treinadores das equipas masculinas fornecem, significativamente, mais informação em termos gerais sobre a própria equipa, no que se referencia às acções inespecíficas do jogo e quando o destinatário é toda a equipa. O facto de actualmente ser permitido ao treinador de Voleibol emitir informação durante o jogo, podendo, inclusive, permanecer junto ao terreno de jogo, é, por si só, motivo suficiente para que o treinador seja tentado a emitir informação, mesmo que não se revele estritamente necessário; consequentemente, poderá emitir informação em excesso, desviando a atenção dos jogadores e dificultando o feedback intrínseco.
CORRESPONDÊNCIA

Isabel Maria Ribeiro Mesquita

Faculdade de Ciências do Desporto

e de Educação Física

Universidade do Porto

Rua Dr. Plácido Costa, 91

4200-450 Porto, Portugal

imesquita@fcdef.up.pt 


\section{REFERÊNCIAS BIBLIOGRÁFICAS}

1. Bellack, A.; Liebard, H.; Hyman, R. \& Smith, F. (1966). The language of the classroom. Teachers College. New York: Columbia University Press.

2. Bloom, G. A.; Durand-Bush, N.; Salmela, J. H. (1997). Preand Postcompetition Routines of Expert Coaches of Team Sports. Sport Psychol, 11: 127-141

3. Cloes, M.; Delhaes, J. ; Piéron, M. (1993). Analyse des comportements d' entraineurs de volley-ball pendant des recontres officielles. Sport, 141: 16-25.

4. Cox, R. H. (1994). Sport psychology: Concepts and applications. Dubuque, IA: WCB Brown y Benchmark.

5. Cunha, F. (1996). A eficácia ofensiva em voleibol. Estudo da relação entre a qualidade do $1^{\circ}$ toque e a eficácia do ataque em voleibolistas portuguesas da $1^{a}$ divisão. Dissertação de Mestrado. F.C.D.E.F.-U.P.

6. Cushion, J. C.; Jones, R. L. (2001). A Systematic Observation of Professional Top-level Youth Soccer Coaches. Journal of Sport Behavior, 24 (4): 354-378.

7. Frohner, B. (1997) Selected individual action and performance profiles. The Coach. FIVB (1): 19-21.

8. Hastie, P. (1999). An Instrument for recording coaches comments and instructions during time-outs. Journal of Sport Behavior, 22 (4): 467-478.

9. Hotz, A. (1999). Corrigir apenas o estritamente necessário, variar o mais possível. Treino Desportivo, 2 (6): 22-36.

10. Isberg, J. (1999). Coaching during elite football games. In: V. Hosek, P. Tilinger \& L. Bilek (Eds.) Proceedings of the $10^{\text {th }}$ European Congress of Sport Psychology. Psychology of sport and exercise: enhancing the quality of life. Prague: Charles University, Faculty of Psysical Education and Sports, 267-270.

11. Ker, W. (1996). Effective Timeout Communication. In: K. S. Asher (ed.) The related elements of the game. The best of Coaching Volleyball Book three. Indianapolis: Masters Press, 106-110.

12. Launder, A.; Piltz, W. (1999). Como dirigir melhor a equipa durante as competições. Treino Desportivo, 7: 24-29.

13. Leith, M. (1992). Um bom treinador tem que ser um bom gestor. Treino Desportivo, 23: 3-13.

14. Martens, R. (1987). Coaches guide to sport psychology. Champaign, IL: Human Kinetics.

15. McGown, C. (1994). Motor Learning: how to teach skills. Science of coaching Volleyball. Champaign IL: Human Kinetics, 1-22.

16. Mesquita, I.; Guerra, I.; Araújo, V. (2002). Processo de Formação do Jovem Jogador de Voleibol. Porto: CEFD.

17. Monteiro, A. (1995). Eficiência do serviço em voleibol. Estudo comparativo dos diferentes tipos de serviço na fase final do campeonato nacional masculina da $1^{a}$ divisão. Dissertação de Mestrado. F.C.D.E.F.-U.P.

18. Moreno, M. P. (2001). Análisis y optimización de la conducta verbal del entrenador de Voleibol durante la dirección de equipo en competición. Tesis Doctoral. Universidade da Extremadura. Cáceres.

19. Moreno, M. P.; Moreno, A.; Cervelló, E.; Ramos, L. A.; Del Villar, F. (In press). Influencias del rendimiento en competición sobre la conducta verbal del entrenador de voleibol. Un estudio en etapas de iniciación. Revista de Entrenamiento Deportivo.

20. Orlick, T. (1986). Psyching for sport. Champaign, IL: Human Kinetics.
21. Pina, R.; Rodrigues, J. (1993). Episódios de informação do treinador e a reacção dos atletas numa situação de competição. In: S. Serpa, J. Alves, V. Ferreira, A. Paula Brito (Eds), Proceedings VIII World Congress of Sport Psychology. Sport Psychology: an integrated approach. ISSP, SPPD. Lisboa: FMH-UTL, 271-274.

22. Pina, R.; Rodrigues, J. (1997). Análise do comportamento do treinador em competição. Estudo dos episódios de informação em voleibol. Pedagogia do Desporto. Estudos 5. Lisboa: FMH-UTL, 71-89.

23. Rink, J. (1994). The Task Presentation in Pedagogy. Quest, 46: $270-280$

24. Rodrigues, J.; Pina, R. (1999). Análise da instrução na competição em voleibol. Pedagogia do Desporto. Estudos 6 . Lisboa: FMH-UTL, 45-53.

25. Salmela, J. (1996). Great job coach. Getting the edge from proven winners. Ottawa: Potentium.

26. Tabachnick, B.G.; Fidell, L.S. (1989). Using Multivariate Statistics. $2^{\text {a }}$ edição. New York: Haper \& Row Publishers.

27. Vasconcelos, M. (1998) Influências da ação desenvolvida pela atacante central na circulação táctica ofensiva sobre a organização do bloco adversário. Dissertação de Mestrado. F.C.D.E.F.-U.P. 